\title{
Stomach cancer mortality among workers exposed to asbestos: a meta-analysis
}

\author{
Wen-jia Peng $\cdot$ Xian-jie Jia $\cdot$ Bing-gan Wei $\cdot$ \\ Lin-sheng Yang $\cdot$ Ying Yu $\cdot$ Lei Zhang
}

Received: 24 July 2014 / Accepted: 26 July 2014 / Published online: 13 August 2014

(C) Springer-Verlag Berlin Heidelberg 2014

\begin{abstract}
Background The relationship between asbestos and stomach cancer is not well understood because of small number of cases. This study aimed to determine the incidence and mortality of stomach cancer among workers exposed to asbestos based on a systematic review and meta-analysis approach.

Methods Relevant English electronic databases were systematically searched for published studies characterizing the risk of developing stomach cancer as a result of asbestos exposure. Standardized mortality rate (SMR) for stomach cancer with its $95 \%$ confidence interval (CI) was pooled using a fixed-/random-effect model in STATA.

Results A total of 32 independent studies were included for the analysis. The overall SMR for stomach cancer was 1.19 (95\% CI 1.06-1.34), with a moderate degree of heterogeneity across the studies $\left(I^{2}=37.6 \%, P=0.011\right)$. Being
\end{abstract}

Electronic supplementary material The online version of this article (doi:10.1007/s00432-014-1791-3) contains supplementary material, which is available to authorized users.

W. Peng $\cdot$ X. Jia $(\bowtie)$

Department of Epidemiology and Health Statistics, Bengbu

Medical College, Bengbu, Anhui, China

e-mail: xjjia@139.com

\section{B. Wei $\cdot$ L. Yang}

Institute of Geographic Sciences and Natural Resources

Research, Chinese Academy of Sciences, Beijing, China

Y. Yu

Department of Physiology, Bengbu Medical College, Bengbu, Anhui, China

\section{Zhang $(\bowtie)$}

Kirby Institute, The University of New South Wales, Sydney, Australia

e-mail: lzhang@kirby.unsw.edu.au male, exposure to crocidolite, miners, studies conducted in Europe and Oceania, and long study follow-up ( $\geq 25$ years) all contribute to significantly higher SMR. Significant publication bias was observed.

Conclusion Elevated risk of stomach cancer mortality was evidenced among workers exposed to crocidolite, especially male miners.

Keywords Asbestos $\cdot$ Stomach cancer $\cdot$ Standardized mortality rate $\cdot$ Meta-analysis

\section{Introduction}

As the rapid development of industrialization, the humanity while pollution causing own health and safety. Asbestos is an important non-metallic mineral raw material and is generally divided into two specific structures: serpentine and amphibole. The most common types of asbestos fiber used are chrysolite (white) asbestos, which is a serpentine mineral, amosite (brown), and crocidolite (blue) asbestos, which is an amphibole mineral (IARC 1977). The colors are seen in clean fibers and may not be clearly visible when the fibers are mixed with other material. Asbestos is widely used in buildings, vehicles and industries because of its chemical and physical properties of high tensile strength, flexibility, heat resistance and good thermal and electrical insulation properties.

It is estimated that there were 125 million people worldwide working in environments exposed to asbestos (WHO 2006). Asbestos exposure has caused a series of health problems. Three main diseases are currently related to asbestos exposure: asbestosis, lung cancer, and mesothelioma. Around 43,000 people died from malignant mesothelioma, and a much larger number of lung cancer died due to occupational exposure to asbestos (Driscoll et al. 2005). 
A large volume of studies have discussed the relationship between asbestos exposure and malignant tumors. Several meta-analyses have suggested an increased risk of cancers, including ovarian cancer, colorectal cancer, and laryngeal cancer.

Stomach cancer is the fourth common cancer worldwide, followed by lung, breast, colon and rectum, and the second most frequent cause of cancer death. Stomach cancer is observed predominantly in males, with a ratio of $2: 1$ (Jemal et al. 2011). Up to now, the precise pathogenesis of stomach cancer is not yet fully understood. A grow body of evidence suggests genetic factors, and environmental triggers are contributed to the development of stomach cancer. Occupational exposure to asbestos has been intensely addressed as a possible risk factor for stomach cancer. However, the conclusions did not reach a consensus.

Considering the limitations of a single research, the aim of this study was to review the epidemiology studies that have reported the association of asbestos exposure with stomach cancer incidence or mortality and perform a metaanalysis of those studies to quantitatively evaluate whether exposure to asbestos could cause stomach cancer.

\section{Materials and methods}

\section{Selection of studies}

Studies were identified by searching PubMed, Elsevier, and Web of Science databases using the following keywords: "cancer," "stomach cancer," "gastric cancer," "asbestos," "crocidolite," "chrysotile," "amosite," "mortality," "standardized mortality ratio (SMR)," and "cohort." Language was restricted to English and Chinese. The reference lists of relevant publications were also reviewed manually to identify additional studies. As some papers on the same cohort study were published several times, only the newest or most informative single article was included. When one article reported different industry types in one cohort, we treated them independently.

\section{Inclusion criteria}

To be eligible for inclusion, studies had to meet the following criteria:

1. they must have a cohort design with fully published;

2. they must have a unequivocal evidence of asbestos exposure;

3. they must provide SMR or standardized incidence rate. We accepted the standardized mortality rate as a surrogate of incidence, because of the relatively short survival time and the high case fatality rate of stomach cancer.

\section{Exclusion criteria}

The following studies were excluded: (1) overlapping articles or duplicate data; (2) articles conducted on animal; (3) review article without original data; (4) insufficient information; and (5) occupational exposure to a variety of factors, not just asbestos.

\section{Data extraction}

To minimize the bias and to improve the reliability, two reviewers checked all potentially relevant studies independently. Potential disagreements were resolved by consensus. The following information was extracted from each study: name of first author, publication year, original country, industry type, asbestos type, cohort size, period of employment, follow-up period, total person-years of observation and total observed numbers of cancers, and fixed-/random-effect model.

\section{Statistical analysis}

A SMR with its corresponding $95 \%$ confidence interval (CI) extracted from each study was combined based on a fixed-effect (Mantel-Haenszel method) or a random-effect (DerSimonian-Laird method) model (Mantel and Haenszel 1959; DerSimonian and Laird 1986). Given the significant amount of heterogeneity, only the random-effect estimates are presented. The heterogeneity among studies was assessed Cochran's $Q$ test and $I^{2}$ metric. For the $Q$ statistic, a $P$ value $<0.10$ was considered statistically significant for heterogeneity; for $I^{2}$, a value ranged from 0 to $100 \%$, and value $>25 \%$ represented the possibility for substantial heterogeneity (Higgins and Thompson 2002). Meta-regression was performed to assess the potentially important variables exerting substantial impact on between-study heterogeneity. The leave-one-out sensitivity analysis was conducted to determine whether our assumptions or decisions had a major effect on the results of the review by omitting each study (Tobias 1999). Evaluation of publication bias was first assessed by the Begg's funnel plot (Begg and Mazumdar 1994) and then performed for each of the pooled study groups using Egger's bias indicator test (Egger et al. 1997).

\section{Results}

Characteristics of eligible studies

The flow chart of literatures selection was provided in Fig. 1. Based on the predetermined search strategies, a total of 1,327 papers were identified. We carefully reviewed the abstracts or full texts of these papers. Totally, forty cohorts from 32 independent studies (Harding et al. 2009; Musk 


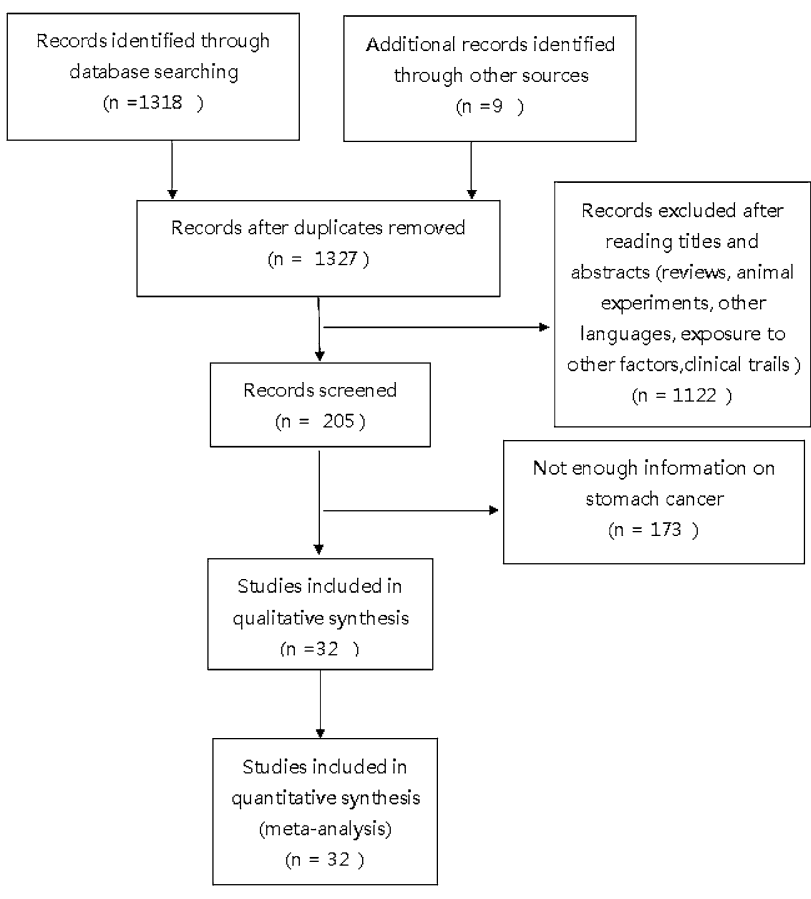

Fig. 1 Flow diagram of articles selection process

et al. 2008; Wang et al. 2013; Du et al. 2012; Menegozzo et al. 2011; Tomioka et al. 2011; Pesch et al. 2010; Clin et al. 2009; Loomis et al. 2009; Pira et al. 2009; Frost et al. 2008; Reid et al. 2008; Hein et al. 2007; Kjaerheim et al. 2005; Pira et al. 2005; Wilczyńska et al. 2005; Reid et al. 2004; Smailyte et al. 2004; Sun et al. 2003; de La Provôté et al. 2002; Szeszenia-Dabrowska et al. 2002; Berry et al. 2000; Battista et al. 1999; Germani et al. 1999; Kurumatani et al. 1999; Tsai et al. 1996; Dement et al. 1994; Tarchi et al. 1994; Magnani et al. 2008; Raffn et al. 1989; Armstrong et al. 1988; Acheson et al. 1982) met the criteria for inclusion in the meta-analysis. Table 1 summarized all the available cohort studies with acknowledged asbestos exposure, which we have been able to identify. The study from Acheson et al. (1982) reported two different cohorts, which were treated independently. Studies conducted by Dement et al. (1994) and Brown et al. (1994) were based on the same cohort, and the former one was subjected to the final analysis. Two studies (Kang et al. 1997 and Sun et al. 1997) were excluded because of reporting proportionate mortality ratios for stomach cancer.

Five studies (Clin et al. 2009; Kjaerheim et al. 2005; Reid et al. 2004; Smailyte et al. 2004; and de La Provôté et al. 2002) reported findings on stomach cancer incidence, and the remaining studies were based on mortality. Most studies were performed in Europe, five in Asia (Wang et al. 2013; Du et al. 2012; Tomioka et al. 2011; Sun et al. 2003; Kurumatani et al. 1999), three in America (Loomis et al. 2009; Hein et al. 2007; and Tsai et al. 1996), and four in Oceania (Musk et al. 2008; Reid et al. 2008, 2004; and Armstrong et al. 1988). Thirteen studies (Musk et al. 2008; Menegozzo et al. 2011; Tomioka et al. 2011; Pesch et al. 2010; Pira et al. 2009; Kjaerheim et al. 2005; Reid et al. 2004; Szeszenia-Dabrowska et al. 2002; Battista et al. 1999; Kurumatani et al. 1999; Kurumatani et al. 1999; Raffn et al. 1989; and Armstrong et al. 1988) were conducted only in male cohort, and five cohorts (Reid et al. 2004; Sun et al. 2003; Germani et al. 1999; Magnani et al. 2008; and Acheson et al. 1982) included only female. The main type of industries included refitting shipyard, mining, textile, and cement. Only six studies (Harding et al. 2009; Musk et al. 2008; Frost et al. 2008; Kjaerheim et al. 2005; Raffn et al. 1989; and Armstrong et al. 1988) reported a significant association of excess asbestos exposure with stomach cancer risk.

Quantitative data synthesis

As shown in Fig. 2, summarizing the evidence from these 32 studies, the combined SMR based on a random-effect model for stomach cancer among asbestos-exposed workers was 1.19 (95\% CI 1.06-1.34), with a moderate degree of heterogeneity among the studies $(Q=60.85, P=0.011$, $\left.I^{2}=37.6 \%\right)$.

Subgroup analysis by basic characteristics

Pooled SMR for stomach cancer among asbestos-exposed men was 1.30 (95 \% CI 1.16-1.45) with no significant heterogeneity (Figure S1). A significantly increased risk of stomach cancer for cohorts exposed to only crocidolite $(\mathrm{SMR}=1.55,95 \% \mathrm{CI} 1.27-1.89)$ and mixed asbestos (OR $1.2295 \%$ CI 1.06-1.41) was observed. Moderate heterogeneity was detected for subgroup of mixed asbestos (Figure S2). Pooled estimates were significant for the outcome of mortality (SMR $=1.19,95 \%$ CI 1.04-1.35) (Figure S3). Pooed SMRs were increased for European $(\mathrm{SMR}=1.21$, $95 \%$ CI 1.05-1.40) and Oceanian cohorts $(\mathrm{SMR}=1.53$, $95 \%$ CI 1.26-1.86) compared with cohorts from Asian and American, for which there appeared to be no increase in stomach cancer mortality (Figure S4). Worker from mining appeared an elevated risk of stomach cancer reported exposure to asbestos (SMR $=1.43,95 \%$ CI 1.20-1.70) (Figure S5). The long study follow-up ( $\geq 25$ years) reported a significantly excess risk of stomach cancer $(\mathrm{SMR}=1.26$, $95 \%$ CI 1.11-1.42) (Figure S6). The detail results are presented in Table 2.

\section{Meta-regression}

Since there was moderate heterogeneity among included studies, a univariate meta-regression analysis was 


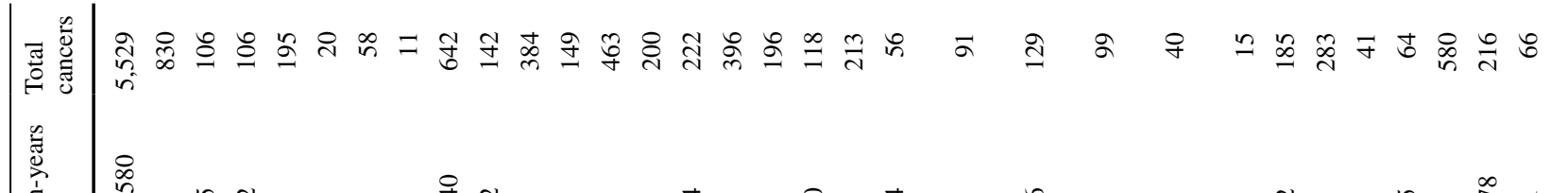

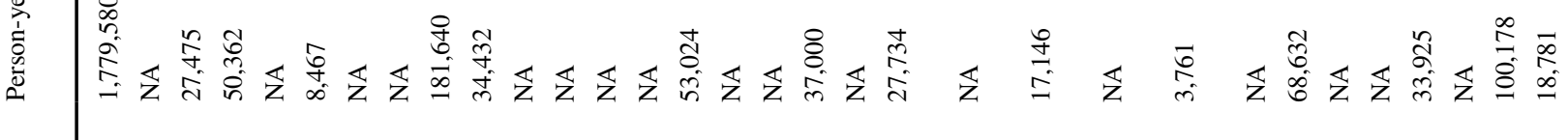

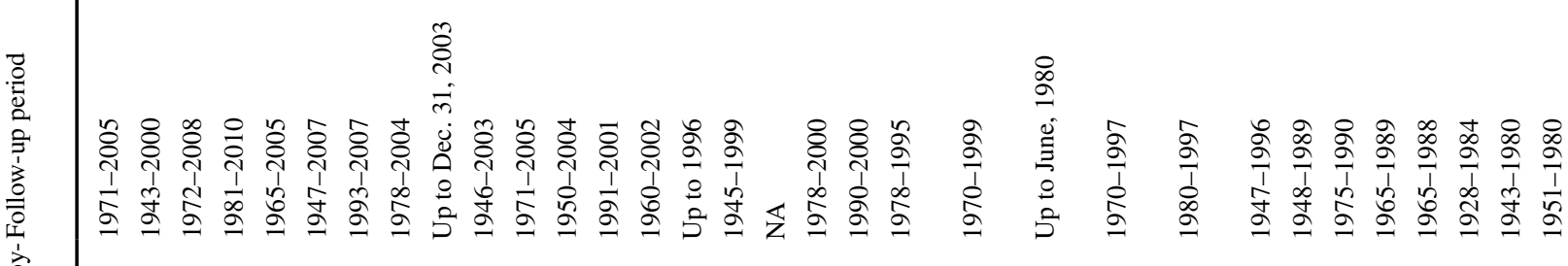

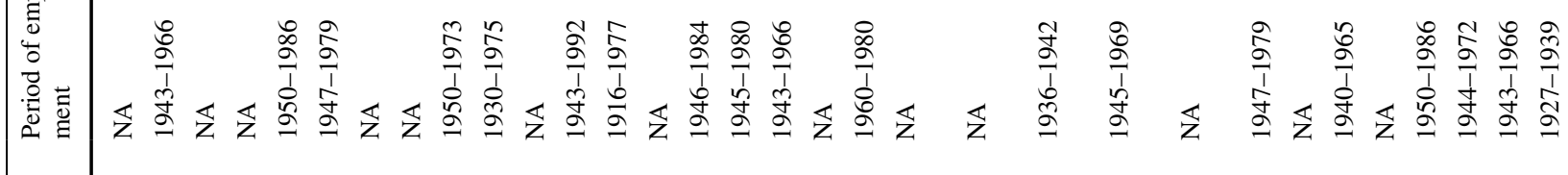

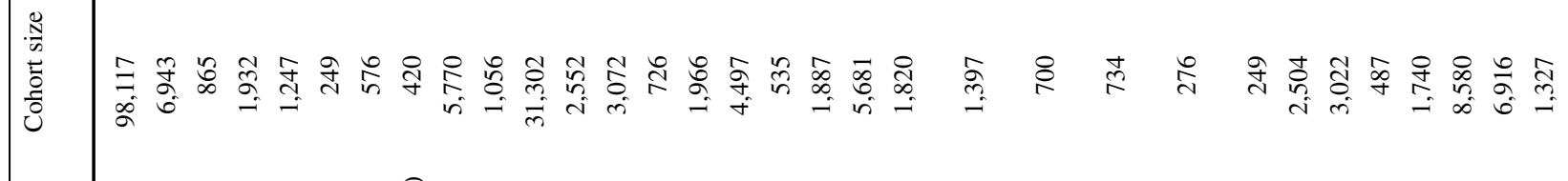

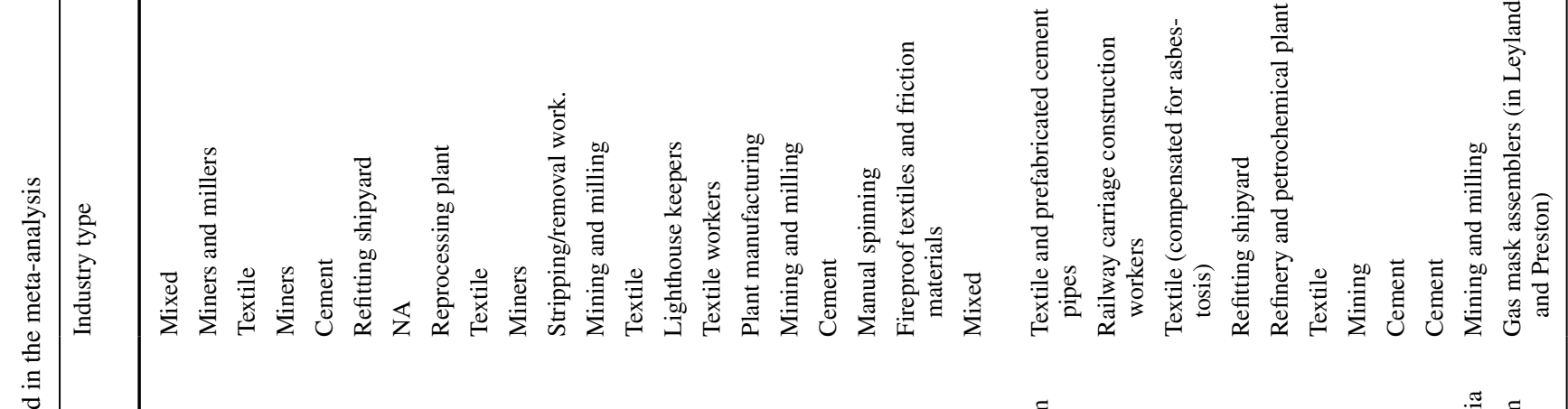

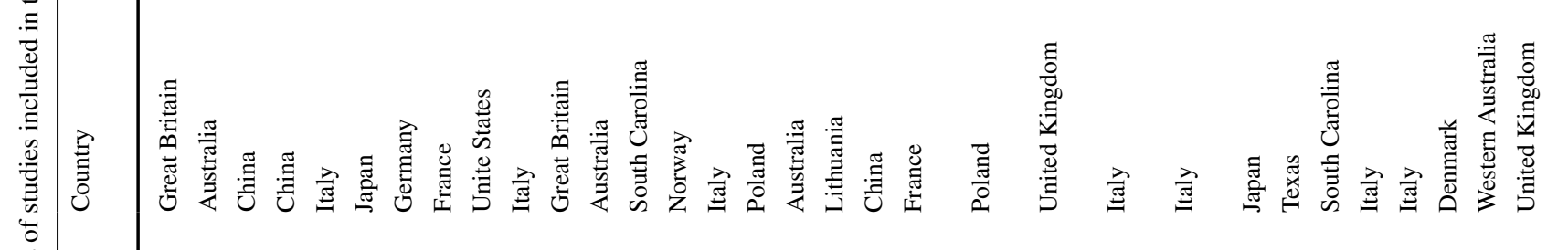

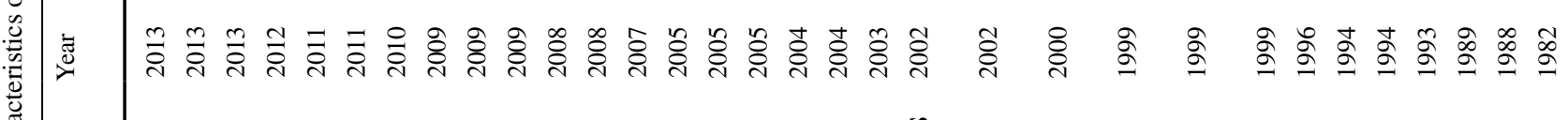

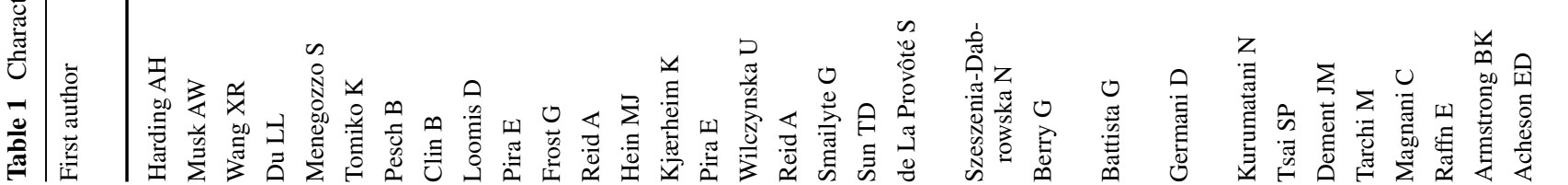



cancer risk associated with the asbestos exposure. The squares and horizontal lines correspond to SMR and $95 \% \mathrm{CI}$ of each included study. The area of squares represents weight of individual study. The diamond represents the summary SMR and $95 \% \mathrm{CI}$
Fig. 2 Forest plot of stomach

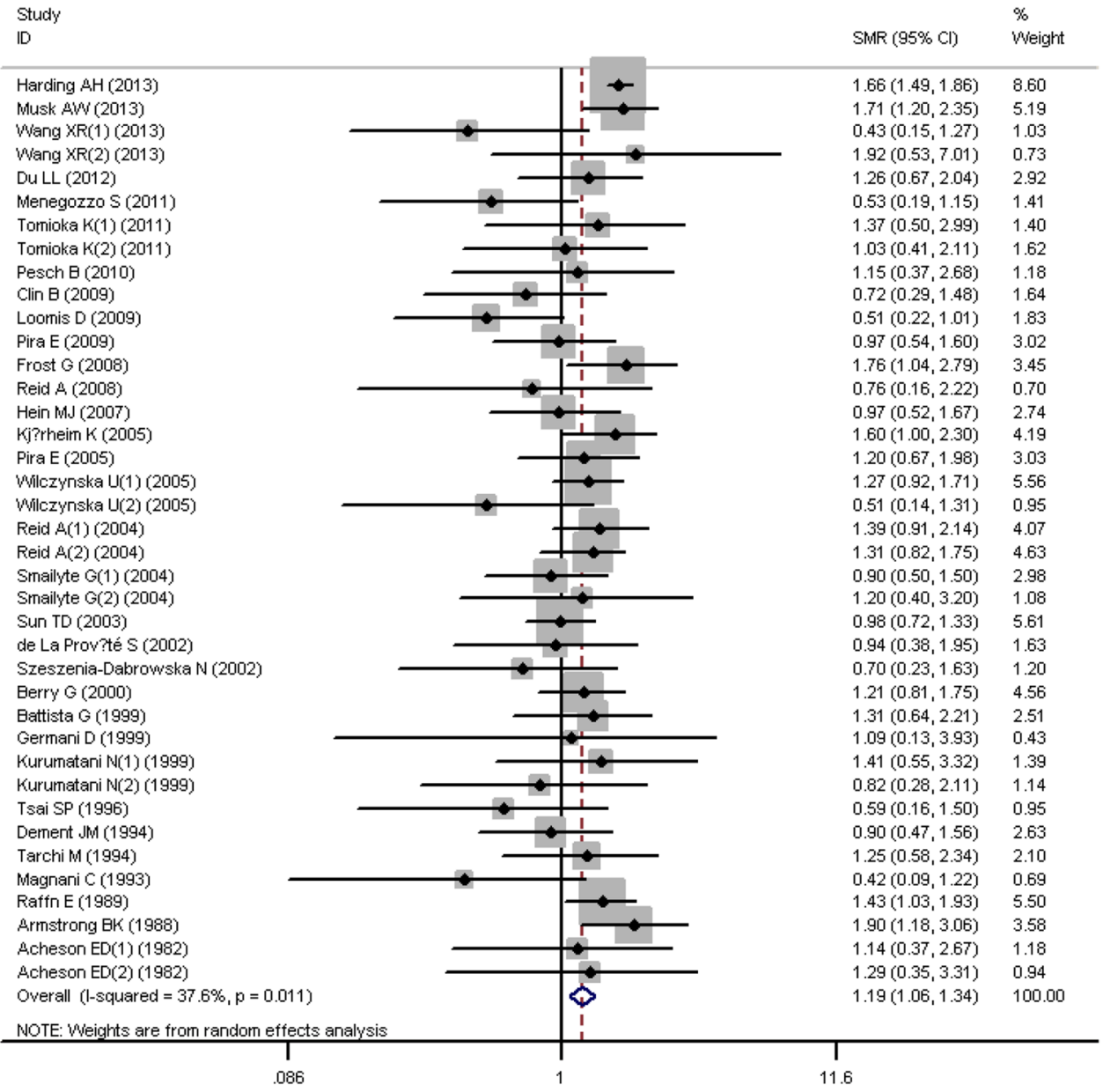

performed to explore the potential source of heterogeneity (Table 3$)$. The results suggested that follow-up period was the significant source of heterogeneity $(P=0.039$, $\tau=0.01664, I_{\text {res }}^{2}=22.08 \%$, Adj $\left.R^{2}=43.78 \%\right)$. Including gender in the regression model virtually eliminated any degree of heterogeneity $\left(P=0.035, \tau=0, I_{\text {res }}^{2}=0.00 \%\right.$, Adj $R^{2}=100.00 \%$ ). Other covariates (type of asbestos, type of outcome, region, type of industry, sample size) could not explain the heterogeneity.

Sensitivity analysis

As shown in Fig. 3, the corresponding pooled SMRs were not significantly altered by exclusion of any one study, which suggested stability of our results.

\section{Evaluation of publication bias}

Both Begg's funnel plot and Egger's test were performed to assess the publication bias. As a result, the funnel plot was not symmetrical, suggesting potential publication bias. By using the trim and fill method, the adjusted estimation was attenuated but remained significant (data not shown).

\section{Discussion}

Asbestos has been classified as the confirmed carcinogen by International Agency for Research on Cancer (IARC). There are strong epidemiological and other evidences supporting that occupational asbestos exposure results in an increased risk of lung cancer and mesothelioma. Whether asbestos fibers are associated with the development of other cancers is still investigation. The majority of cohort studies and literature reviews attempted to answer the question on an association between asbestos exposure and gastrointestinal cancer, but the results are inconclusive. IARC suggested that the association of asbestos exposure with cancers of digestive system is "sufficient" in 1987 (IARC 1987); however, in 2006, US Institute of Medicine Committee indicated that the evidence is "suggestive but not sufficient" (2006).

In current study, we quantitatively assessed the relationship of excessive exposure to asbestos with stomach cancer risk by applying a meta-analysis technique based on 32 independent literatures. Our results revealed an increased stomach cancer risk among workers exposed to asbestos. In other words, workers exposed to asbestos have 1.19 times 
Table 2 Pooled results of stomach cancer with asbestos exposure by study characteristics

\begin{tabular}{|c|c|c|c|}
\hline Study characteristics & No. of studies & $\operatorname{SMR}(95 \% \mathrm{CI}), P$ & Heterogeneity test $\left(Q, I^{2}, P\right)$ \\
\hline All & 32 & 1.19 (1.06-1.34), 0.003 & $60.85,37.6 \%, 0.011$ \\
\hline \multicolumn{4}{|l|}{ Gender } \\
\hline Male & 25 & $1.30(1.16-1.45),<0.001$ & $27.16,11.6 \%, 0.297$ \\
\hline Female & 11 & $0.97(0.76-1.24), 0.788$ & $4.65,0.0 \%, 0.913$ \\
\hline \multicolumn{4}{|l|}{ Type of asbestos } \\
\hline Chrysotile & 9 & $0.97(0.80-1.17), 0.721$ & $7.47,0.0 \%, 0.588$ \\
\hline Crocidolite & 4 & $1.55(1.27-1.89),<0.001$ & $2.04,0.0 \%, 0.565$ \\
\hline Mix & 19 & 1.22 (1.06-1.41), 0.002 & $34.30,32.9 \%, 0.061$ \\
\hline \multicolumn{4}{|l|}{ Type of outcome } \\
\hline Incidence & 5 & $1.21(0.97-1.52), 0.094$ & $4.94,0.0 \%, 0.423$ \\
\hline Mortality & 27 & 1.19 (1.04-1.35), 0.009 & $54.59,43.2 \%, 0.006$ \\
\hline \multicolumn{4}{|l|}{ Region } \\
\hline Europe & 20 & $1.21(1.05-1.40), 0.009$ & $34.63,36.5 \%, 0.042$ \\
\hline Asia & 5 & $1.04(0.84-1.30), 0.711$ & $5.11,0.0 \%, 0.646$ \\
\hline America & 3 & $0.74(0.48-1.13), 0.161$ & $1.90,0.0 \%, 0.387$ \\
\hline Oceania & 4 & $1.53(1.26-1.86),<0.001$ & $3.14,0.0 \%, 0.535$ \\
\hline \multicolumn{4}{|l|}{ Type of industry } \\
\hline Refitting shipyard & 2 & $1.14(0.73-1.79), 0.556$ & $0.84,0.0 \%, 0.839$ \\
\hline Mining & 6 & $1.43(1.20-1.70),<0.001$ & $5.72,0.0 \%, 0.455$ \\
\hline Textile & 8 & $0.94(0.77-1.15), 0.545$ & $6.64,0.0 \%, 0.576$ \\
\hline Cement & 5 & $1.15(0.91-1.46), 0.232$ & $7.84,36.3 \%, 0.165$ \\
\hline Mix & 3 & $1.36(0.95-1.94), 0.095$ & $5.18,61.4 \%, 0.075$ \\
\hline \multicolumn{4}{|c|}{ Follow-up period (years) } \\
\hline$<25$ & 7 & 0.97 (0.79-1.19), 0.778 & $0.43,0.0 \%, 1.000$ \\
\hline$\geq 25$ & 25 & $1.26(1.11-1.42),<0.001$ & $48.33,35.9 \%, 0.024$ \\
\hline
\end{tabular}

Table 3 Meta-regression analysis to explore potential source of heterogeneity

\begin{tabular}{|c|c|c|c|c|c|}
\hline Variable & Coefficient & $P$ value & $\tau$ & $I_{\text {res }}^{2}(\%)$ & $\operatorname{Adj} R^{2}(\%)$ \\
\hline Gender $(1=$ male, $2=$ female $)$ & -0.3086 & 0.035 & 0 & 0.00 & 100.00 \\
\hline Type of asbestos $(1=$ chrysotile, $2=$ crocidolite, $3=\operatorname{mix})$ & 0.0971 & 0.137 & 0.02135 & 24.40 & 27.85 \\
\hline Type of outcome $(1=$ incidence, $2=$ mortality $)$ & 0.0344 & 0.825 & 0.03137 & 36.22 & -6.03 \\
\hline Region $(1=$ Europe, $2=$ Asia, $3=$ America, $4=$ Oceania $)$ & 0.0363 & 0.460 & 0.03243 & 37.32 & -9.59 \\
\hline $\begin{array}{l}\text { Type of industry }(1=\text { refitting shipyard, } 2=\text { mining, } 3=\text { textile, } \\
4=\text { cement, } 5=\text { mix, } 6=\text { other })\end{array}$ & 0.0106 & 0.752 & 0.03053 & 33.73 & -3.16 \\
\hline Sample size $(1=<500,2=500-1,000,3=>1,000)$ & 0.0037 & 0.966 & 0.03118 & 35.18 & -5.37 \\
\hline Follow-up period $(1=<25,2=\geq 25)$ & 0.2870 & 0.039 & 0.01809 & 23.93 & 43.61 \\
\hline
\end{tabular}

of suffering from stomach cancer compared with the general population.

Higher risk of stomach cancer was observed in male workers. It was not surprising that male may have more chances to exposure to other risk factors, such as smoking or alcohol habit. Lifestyle exposure to alcohol and smoking were associated with increased stomach cancer risks. Studies have showed that cigarette smoking may play the most harmful role in the initial development of stomach cancer and that drinking alcohol may promote the process (Li et al. 2012).
We found an excess mortality of stomach cancer in miners group, which is consistent with the majority of the miner cohorts. Musk et al. (2008) identified a slightly increased risk of mortality from stomach cancer in miners and millers cohort at Wittenoom. Wang et al. (2012) also found excess mortality of gastrointestinal cancers in the miner group. A substantial excess in mortality from gastrointestinal cancers was reported in the Quebec miner cohort (McDonald et al. 1980). A case-control study showed a significantly elevated risk of GI cancers in the miners who had a prolong exposure to coal mine dust (Ames 1983). 
Fig. 3 Sensitivity analysis by removing each study in each turn. Rows represent the results of meta-analysis of all studies except the omitted study named in that row. Omission of any study did not affect the whole estimate results significantly

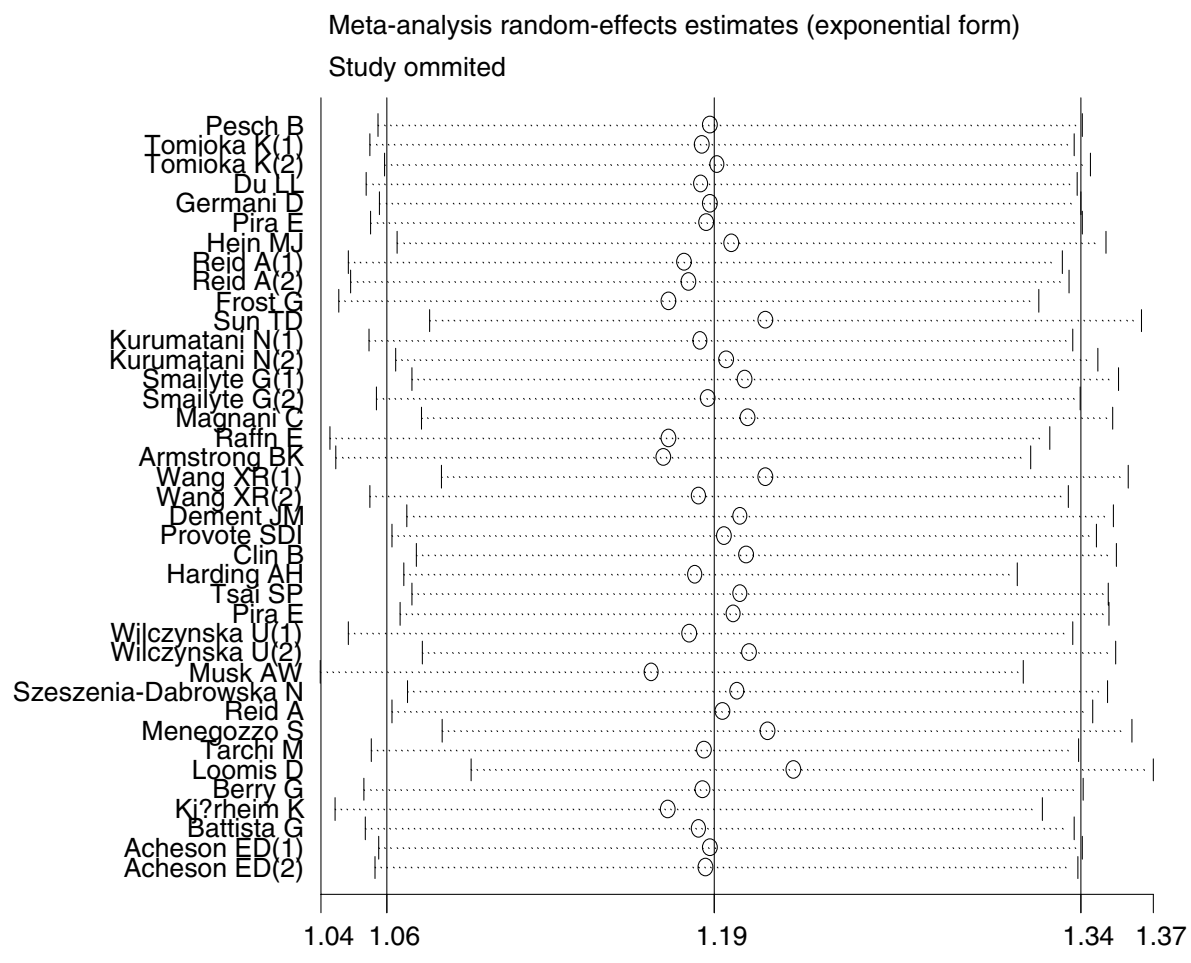

Results from subgroup analysis by follow-up period found that higher risk of stomach cancer was observed in follow-up period above 25 years, which seems to indirectly suggest a dose-response relation.

The exact mechanisms of asbestos exposure leading to stomach cancer are not fully understood. They may be due to the chronic inflammation in stomach tissue caused by persistent presence of asbestos fibers. Kogan et al. (1987) performed an experiment by continuous contact of the stomach wall with asbestos in rats to understand the role of asbestos in the etiology of stomach cancer. Experiment suggested that the tumors in the stomach and the adjacent part of the abdominal cavity were induced by asbestos.

Considering moderate heterogeneity among studies, a meta-regression approach was conducted by adjusting for the covariates to explore the potential important sources. We found gender and follow-up period as the important contributors to the between-study heterogeneity.

Inherent properties of asbestos may affect its carcinogenicity, including fiber diameter and length, surface properties of the fiber, and the fiber durability. The diameter of crocidolite fibers is the finest followed by chrysotile, amosite, and anthophyllite, and was considered the most harmful to human health. In subgroup analysis by asbestos type, workers exposed only to crocidolite found a significant association.

Consistency of evaluation indicators is important for a meta-analysis as different outcomes may introduce potential heterogeneity. The outcome of five studies is a standardized incidence rate. Considering higher death rate and lower survival of stomach cancer, we included the five studies to the final analysis. However, a subgroup analysis by outcome was performed, and positive conclusion was only observed in SMR outcomes.

There are some limitations to this study that should be acknowledged. Firstly, available data in our study could not make us further perform interaction and subgroup analysis by confounding factors, such as alcohol and smoking habit or concomitant occupational exposure to other substances or the diameter of fibers. Second, a further dose-response relationship of stomach cancer with asbestos was not able to be performed due to limited data from original cohorts. Third, significant publication bias was observed. The reason may arise from many aspects, such as positive findings tend to be accepted by journals, while negative results are often rejected or not even submitted. Therefore, the results should be interpreted with caution.

In conclusion, this present meta-analysis found that exposure to asbestos is associated with an increased risk of stomach cancer, especially male miners, and crocidolite is more harmful to human beings. Few studies focus on the elucidation of the mechanisms of asbestos leading to stomach cancer, and constant efforts should be made to clarify the association of asbestos exposure with stomach cancer.

Acknowledgments This work was financially supported by National Natural Science Foundation of China (71103002/41071064). 
Conflict of interest The authors have declared that no conflict of interest exists.

\section{References}

Acheson ED, Gardner MJ, Pippard EC, Grime LP (1982) Mortality of two groups of women who manufactured gas masks from chrysotile and crocidolite asbestos: a 40-year follow-up. Br J Ind Med 39(4):344-348

Ames RG (1983) Gastric cancer and coal mine dust exposure: a casecontrol study. Cancer 52:1346-1350

Armstrong BK, de Klerk NH, Musk AW, Hobbs MS (1988) Mortality in miners and millers of crocidolite in Western Australia. Br J Ind Med 45(1):5-13

Battista G, Belli S, Comba P, Fiumalbi C, Grignoli M, Loi F, Orsi D, Paredes I (1999) Mortality due to asbestos-related causes among railway carriage construction and repair workers. Occup Med (Lond) 49(8):536-539

Begg CB, Mazumdar M (1994) Operating characteristics of a rank correlation test for publication bias. Biometrics 50:1088-1101

Berry G, Newhouse ML, Wagner JC (2000) Mortality from all cancers of asbestos factory workers in east London 1933-80. Occup Environ Med 57(11):782-785

Brown DP, Dement JM, Okun A (1994) Mortality patterns among female and male chrysotile asbestos textile workers. J Occup Med 36(8):882-888

Clin B, Morlais F, Dubois B, Guizard AV, Desoubeaux N, Marquignon MF, Raffaelli C, Paris C, Galateau-Salle F, Launoy G, Letourneux M (2009) Occupational asbestos exposure and digestive cancersa cohort study. Aliment Pharmacol Ther 30(4):364-374

Committee on Asbestos: Selected Health Effects (2006) Asbestos: selected cancers. National Academies Press, New York

de La Provôté S, Desoubeaux N, Paris C, Letourneux M, Raffaelli C, Galateau-Salle F, Gignoux M, Launoy G (2002) Incidence of digestive cancers and occupational exposure to asbestos. Eur $\mathrm{J}$ Cancer Prev 11(6):523-528

Dement JM, Brown DP, Okun A (1994) Follow-up study of chrysotile asbestos textile workers: cohort mortality and case-control analyses. Am J Ind Med 26(4):431-447

DerSimonian R, Laird N (1986) Meta-analysis in clinical trials. Control Clin Trials 7:177-188

Driscoll T, Nelson DI, Steenland K, Leigh J, Concha-Barrientos M, Fingerhut M (2005) The global burden of disease due to occupational carcinogens. Am J Ind Med 48(6):419-431

Du L, Wang X, Wang M, Lan Y (2012) Analysis of mortality in chrysotile asbestos miners in China. J Huazhong Univ Sci Technolog Med Sci 32(1):135-140

Egger M, Davey SG, Schneider M, Minder C (1997) Bias in metaanalysis detected by a simple, graphical test. BMJ 315:629-634

Frost G, Harding AH, Darnton A, McElvenny D, Morgan D (2008) Occupational exposure to asbestos and mortality among asbestos removal workers: a Poisson regression analysis. Br J Cancer 99(5):822-829

Germani D, Belli S, Bruno C, Grignoli M, Nesti M, Pirastu R, Comba P (1999) Cohort mortality study of women compensated for asbestosis in Italy. Am J Ind Med 36(1):129-134

Harding AH, Darnton A, Wegerdt J, McElvenny D (2009) Mortality among British asbestos workers undergoing regular medical examinations (1971-2005). Occup Environ Med 66(7):487-495

Hein MJ, Stayner LT, Lehman E, Dement JM (2007) Follow-up study of chrysotile textile workers: cohort mortality and exposureresponse. Occup Environ Med 64(9):616-625

Higgins JP, Thompson SG (2002) Quantifying heterogeneity in a meta-analysis. Stat Med 21:1539-1558
IARC (1977) Monographs on the evaluation of carcinogenic risk of chemicals to man. Vol. 14, Asbestos. International Agency for Research on Cancer, Lyon

IARC (1987) Overall evaluations of carcinogenicity. International Agency for Research on Cancer, Lyon

Jemal A, Bray F, Center MM et al (2011) Global cancer statistics. CA Cancer J Clin 61:69-90

Kang SK, Burnett CA, Freund E, Walker J, Lalich N, Sestito J (1997) Gastrointestinal cancer mortality of workers in occupations with high asbestos exposures. Am J Ind Med 31(6):713-718

Kjaerheim K, Ulvestad B, Martinsen JI, Andersen A (2005) Cancer of the gastrointestinal tract and exposure to asbestos in drinking water among lighthouse keepers (Norway). Cancer Causes Control 16(5):593-598

Kogan FM, Vanchugova NN, Frasch VN (1987) Possibility of inducing glandular stomach cancer in rats exposed to asbestos. Br J Ind Med 44(10):682-686

Kurumatani N, Natori Y, Mizutani R, Kumagai S, Haruta M, Miura H, Yonemasu K (1999) A historical cohort mortality study of workers exposed to asbestos in a refitting shipyard. Ind Health 37(1):9-17

Li L, Ying XJ, Sun TT, Yi K, Tian HL, Sun R, Tian JH, Yang KH (2012) Overview of methodological quality of systematic reviews about gastric cancer risk and protective factors. Asian Pac J Cancer Prev 13(5):2069-2079

Loomis D, Dement JM, Wolf SH, Richardson DB (2009) Lung cancer mortality and fibre exposures among North Carolina asbestos textile workers. Occup Environ Med 66(8):535-542

Magnani C, Ferrante D, Barone-Adesi F, Bertolotti M, Todesco A, Mirabelli D, Terracini B (2008) Cancer risk after cessation of asbestos exposure: a cohort study of Italian asbestos cement workers. Occup Environ Med 65(3):164-170

Mantel N, Haenszel W (1959) Statistical aspects of the analysis of data from retrospective studies of disease. J Natl Cancer Inst 22:719-748

McDonald JC, Liddell FDK, Gibbs GW, Eyssen GE, McFonald AD (1980) Dust exposure and mortality in chrysotile mining, 1910 75. Br J Ind Med 37:11-24

Menegozzo S, Comba P, Ferrante D, De Santis M, Gorini G, Izzo F, Magnani C, Pirastu R, Simonetti A, Tùnesi S, Menegozzo M (2011) Mortality study in an asbestos cement factory in Naples, Italy. Ann Ist Super Sanita 47(3):296-304

Musk AW, de Klerk NH, Reid A, Ambrosini GL, Fritschi L, Olsen NJ, Merler E, Hobbs MS, Berry G (2008) Mortality of former crocidolite (blue asbestos) miners and millers at Wittenoom. Occup Environ Med 65(8):541-543

Pesch B, Taeger D, Johnen G, Gross IM, Weber DG, Gube M, MüllerLux A, Heinze E, Wiethege T, Neumann V, Tannapfel A, Raithel HJ, Brüning T, Kraus T (2010) Cancer mortality in a surveillance cohort of German males formerly exposed to asbestos. Int J Hyg Environ Health 213(1):44-51

Pira E, Pelucchi C, Buffoni L, Palmas A, Turbiglio M, Negri E, Piolatto PG, La Vecchia C (2005) Cancer mortality in a cohort of asbestos textile workers. Br J Cancer 92(3):580-586

Pira E, Pelucchi C, Piolatto PG, Negri E, Bilei T, La Vecchia C (2009) Mortality from cancer and other causes in the Balangero cohort of chrysotile asbestos miners. Occup Environ Med 66(12):805-809

Raffn E, Lynge E, Juel K, Korsgaard B (1989) Incidence of cancer and mortality among employees in the asbestos cement industry in Denmark. Br J Ind Med 46(2):90-96

Reid A, Ambrosini G, de Klerk N, Fritschi L, Musk B (2004) Aerodigestive and gastrointestinal tract cancers and exposure to crocidolite (blue asbestos): incidence and mortality among former crocidolite workers. Int J Cancer 111(5):757-761

Reid A, Heyworth J, de Klerk N, Musk AW (2008) The mortality of women exposed environmentally and domestically to blue 
asbestos at Wittenoom, Western Australia. Occup Environ Med 65(11):743-749

Smailyte G, Kurtinaitis J, Andersen A (2004) Cancer mortality and morbidity among Lithuanian asbestos-cement producing workers. Scand J Work Environ Health 30(1):64-70

Sun J, Shibata E, Hisanaga N, Kamijima M, Ichihara G, Huang J, Toida M, Takeuchi Y (1997) A cohort mortality study of construction workers. Am J Ind Med 32(1):35-41

Sun T, Li L, Shi N, Zhang X (2003) A 40-year cohort study on cancer mortality among female workers with manual spinning of chrysotile asbestos. Wei Sheng Yan Jiu 32(6):511-513

Szeszenia-Dabrowska N, Urszula W, Szymczak W, Strzelecka A (2002) Mortality study of workers compensated for asbestosis in Poland, 1970-1997. Int J Occup Med Environ Health 15(3):267-278

Tarchi M, Orsi D, Comba P, De Santis M, Pirastu R, Battista G, Valiani M (1994) Cohort mortality study of rock salt workers in Italy. Am J Ind Med 25(2):251-256

Tobias A (1999) Assessing the influence of a single study in metaanalysis. STB 47:15-17

Tomioka K, Natori Y, Kumagai S, Kurumatani N (2011) An updated historical cohort mortality study of workers exposed to asbestos in a refitting shipyard, 1947-2007. Int Arch Occup Environ Health 84(8):959-967

Tsai SP, Waddell LC, Gilstrap EL, Ransdell JD, Ross CE (1996) Mortality among maintenance employees potentially exposed to asbestos in a refinery and petrochemical plant. Am J Ind Med 29(1):89-98

Wang X, Lin S, Yano E, Qiu H, Yu IT, Tse L, Lan Y, Wang M (2012) Mortality in a Chinese chrysotile miner cohort. Int Arch Occup Environ Health 85(4):405-412

Wang X, Lin S, Yu I, Qiu H, Lan Y, Yano E (2013) Cause-specific mortality in a Chinese chrysotile textile worker cohort. Cancer Sci 104(2):245-249

WHO (World Health Organization) (2006) Elimination of asbestosrelated diseases. Geneva: WHO. Available: http://www.who. int/occupational_health/publications/asbestosrelateddisease/en/ index.html. Accessed 27 April 2010

Wilczyńska U, Szymczak W, Szeszenia-Dabrowska N (2005) Mortality from malignant neoplasms among workers of an asbestos processing plant in Poland: results of prolonged observation. Int $\mathbf{J}$ Occup Med Environ Health 18(4):313-326 